\title{
Trichloroethylene exposure. Biological monitoring by breath and urine analyses
}

\author{
P. O. DROZ AND J. G. FERNÁNDEZ* \\ From the Occupational Health and Industrial Hygiene Service, Chemistry Department of the University of \\ Neuchâtel, Bellevaux 51, 2000 Neuchâtel, Switzerland
}

\begin{abstract}
A mathematical model developed previously has been used to study some aspects of biological monitoring of exposure to trichloroethylene (TRI) by the analysis of this solvent in alveolar air or of its metabolites, trichloroethanol (TCE) and trichloroacetic acid (TCA), in urine. Assuming that a biological control must be representative of the time-weighted average concentration (TWA), it was found that sampling for TRI and TCE analyses must be carried out the morning after the exposure being considered. On the other hand, for a TCA analysis, the timing of urine sampling is not a determinant factor. Theoretical limit concentrations have been set up for these biological indicators, but it is shown that their application must be restricted to exposures which are quantitatively reproducible from one day to the next. In all other cases, it appears that this monitoring method can lead to errors in the estimated exposure concentrations. A tentative method of biological monitoring is therefore proposed. It is based on the analysis of TCE in the urine or TRI in the alveolar air before and after the exposure being monitored. TCA is not considered to be sensitive enough to variations in the inspired concentration to be used as an indicator of a single exposure risk.
\end{abstract}

Although numerous studies have been devoted to the biological monitoring of exposure to trichloroethylene (TRI), this remains a very controversial subject. Several authors have proposed the analysis of the urinary excretion of trichloroacetic acid (TCA) (Frant and Westendorp, 1950; Ahlmark and Forssman, 1951; Elkins, 1954; Grandjean et al., 1955), while others have recommended that of trichloroethanol (TCE) (Lowry et al., 1974), or the sum of these two metabolites (TTC) (Nomiyama, 1971; Ogata et al., 1971; Ikeda et al., 1972). Recently, the analysis of these two compounds in the blood (Müller et al., 1974; Vesterberg et al., 1975) and also that of the pulmonary elimination of TRI (Pfäffli and Backman, 1972; Stewart et al., 1974) were considered. Moreover, the biological limit values proposed for these different indicators (corresponding to an exposure at the TLV) vary considerably from author to author, and the timing of urine, blood or alveolar air sampling is still very arbitrary.

We recently developed a mathematical model (Fernández et al., 1977) which enables the absorp-

*Requests for reprints to Professor Fernández.

Received for publication 28 April 1977

Accepted for publication 25 July 1977 tion, distribution and excretion of TRI, and the kinetics of the formation and elimination of TCE and TCA to be satisfactorily described. This model is used here to study some aspects of the biological monitoring of exposure to TRI, as it enables occupational exposure to be simulated by repeating the absorption of TRI and varying the inhaled concentrations. Under such conditions, the influence of the different exposure factors on the relationship between degree of exposure and excretion of the biological indicators can be studied in the absence of distorting factors such as inter- and intraindividual differences, or analytical accuracy and sensitivity.

This mathematical approach to exposure to TRI enables one to estimate the theoretical biological limit values corresponding to a repeated exposure at $100 \mathrm{ppm}$ (TLV), for the urinary excretion of TCE and TCA and for the pulmonary elimination of TRI. The possibility of applying these limits to the control of occupational exposure is then studied by varying the inhaled concentration of TRI during an exposure (hourly variations) and from one exposure to another (daily variations). Finally, on the basis of the results obtained, a tentative optimal method of biological monitoring is proposed. 


\section{Methods}

The mathematical model and the values of the physiological and metabolic parameters have already been described in detail (Fernández et al., 1977). An alveolar ventilation of $71 / \mathrm{min}$ is used in all the simulations and is determined by using the average energy expenditure of a sedentary person (Scherrer, 1967). Cardiac output, calculated from the alveolar ventilation with a perfusion-ventilation ratio of 1.25 , is $8.75 \mathrm{l} / \mathrm{min}$. The excess of cardiac output, in comparison with the resting state, is considered to perfuse the tissue group MG (muscles and skin).

In order to obtain the urinary concentrations of the two metabolites TCE and TCA, it is supposed that $1 \mathrm{ml}$ of urine is formed per minute. Furthermore, it is considered that the bladder is emptied at $7 \mathrm{am}$, $12 \mathrm{am}, 5 \mathrm{pm}$ and $10 \mathrm{pm}$, and that exposure generally takes place between 8 am-12 am and 1 pm-5 pm.

A constant exposure of eight hours per day, five days per week, repeated week after week, results in a state of equilibrium, so that the concentrations of TRI, TCE and TCA in the body are the same at the beginning of each week. The initial conditions of this steady-state week have been determined by successive approximations (it is considered that the retention is constant throughout the whole exposure period) and used in the mathematical model to simulate four weeks of exposure in order to reach the exact steady-state.

Tables 1 and 2 show the different simulations carried out. In the former, model 1 corresponds to the steady-state week, while models 2 and 3 each represent one week of isolated exposure. Models 4 to 10 , of which the initial conditions are identical to those of model 1 , simulate situations where the exposure concentration varies from day to day (daily variations). In Table 2 , models 11 to 14 correspond to exposures lasting one day at fluctuating concentrations (hourly variations). These exposures took place on Thursday of a steady-state week and have a time-weighted average concentration of $100 \mathrm{ppm}$.

\section{Results and discussion}

\section{BIOLOGICAL LIMITS OF EXPOSURE}

The alveolar air concentrations of TRI corresponding to a repeated exposure at $100 \mathrm{ppm}$ (TLV) can be obtained using model 1 . These concentrations are shown in Table 3 for each day of the week at different post-exposure times. It can be seen that the alveolar air concentrations during the first few hours of post-exposure do not vary much from day to day, while those measured 15 hours after the end of exposure increase considerably from Monday to
Table 1 Simulations of daily variations in the inspired concentration (ppm)

\begin{tabular}{llllllllllll}
\hline Day & \multicolumn{1}{l}{ Model } \\
\cline { 2 - 9 } & 1 & 2 & 3 & 4 & 5 & 6 & 7 & 8 & 9 & 10 \\
\hline Preceding exposure* & 100 & 0 & 0 & 100 & 100 & 100 & 100 & 100 & 100 & 100 \\
Monday & 100 & 100 & 200 & 200 & 100 & 100 & 100 & 100 & 100 & 100 \\
Tuesday & 100 & 100 & 100 & 100 & 200 & 100 & 100 & 100 & 200 & 300 \\
Wednesday & 100 & 100 & 100 & 100 & 100 & 200 & 100 & 100 & 100 & 100 \\
Thursday & 100 & 100 & 100 & 100 & 100 & 100 & 200 & 100 & 200 & 300 \\
Friday & 100 & 100 & 100 & 100 & 100 & 100 & 100 & 200 & 100 & 100 \\
\hline
\end{tabular}

*Concentration of the preceding weeks' exposures.

Table 2 Simulations of hourly variations in the inspired concentration (ppm)

\begin{tabular}{lrrrrllllll}
\hline Model & \multicolumn{1}{l}{ Hours of exposure } \\
\cline { 2 - 9 } & 1 & 2 & 3 & 4 & 5 & 6 & 7 & 8 & 9 \\
\hline 11 & 50 & 50 & 50 & 50 & 0 & 150 & 150 & 150 & 150 \\
12 & 150 & 150 & 150 & 150 & 0 & 50 & 50 & 50 & 50 \\
13 & 180 & 180 & 180 & 180 & 0 & 20 & 20 & 20 & 20 \\
14 & 50 & 150 & 50 & 150 & 0 & 50 & 150 & 50 & 150 \\
\hline
\end{tabular}

Table 3 Alveolar air concentrations ( $\mathrm{ppm}$ ) of TRI during a steady-state week of exposure at 100 ppm (model 1)

\begin{tabular}{|c|c|c|c|c|c|}
\hline \multirow[t]{2}{*}{ Day of the week } & \multicolumn{5}{|c|}{ Exposure time } \\
\hline & $\begin{array}{l}0 \text { min } \\
5 \mathrm{pm}\end{array}$ & $\begin{array}{l}30 \text { min } \\
530 \mathrm{pm}\end{array}$ & $\begin{array}{l}1 \mathrm{hr} \\
6 \mathrm{pm}\end{array}$ & $\begin{array}{l}2 \mathrm{hr} \\
7 \mathrm{pm}\end{array}$ & $\begin{array}{l}15 \mathrm{hr} \\
8 \mathrm{am} \text { next day }\end{array}$ \\
\hline $\begin{array}{l}\text { Monday } \\
\text { Tuesday } \\
\text { Wednesday } \\
\text { Thursday } \\
\text { Friday }\end{array}$ & $\begin{array}{l}33 \cdot 07 \\
33 \cdot 34 \\
33 \cdot 50 \\
33 \cdot 60 \\
33 \cdot 67\end{array}$ & $\begin{array}{l}13 \cdot 59 \\
13 \cdot 85 \\
14 \cdot 02 \\
14 \cdot 12 \\
14 \cdot 18\end{array}$ & $\begin{array}{l}8 \cdot 64 \\
8 \cdot 90 \\
9 \cdot 06 \\
9 \cdot 16 \\
9 \cdot 22\end{array}$ & $\begin{array}{l}3 \cdot 84 \\
4 \cdot 09 \\
4 \cdot 25 \\
4 \cdot 35 \\
4 \cdot 41\end{array}$ & $\begin{array}{l}0 \cdot 79 \\
0 \cdot 99 \\
1 \cdot 11 \\
1 \cdot 18 \\
1 \cdot 23\end{array}$ \\
\hline
\end{tabular}

Friday. The control of exposure to TRI by alveolar air analysis does not, therefore, depend only on the post-exposure time of analysis but also on the day considered.

Figure 1 shows the urinary concentrations of TCE, TCA and TTC during the course of a steady-state week of exposure at $100 \mathrm{ppm}$ (model 1). The concentration of TCA in the urine increases only slightly during the course of the week and only very little during each day. The timing of urine sampling does not, therefore, appear to be an important factor in the interpretation of biological monitoring by TCA. With regard to TCE and TTC, it can be seen that the urinary excretion increases considerably at the beginning of the week, and then becomes stable during the second half. In addition, the concentrations vary considerably throughout the day: they are lower at 12 am than at 7 am (except on Monday), considerably higher at $5 \mathrm{pm}$, and maximal at $10 \mathrm{pm}$. The timing of urine sampling is, therefore, a determinant factor in the biological evaluation of the degree of exposure by the analysis of TCE or TTC. 


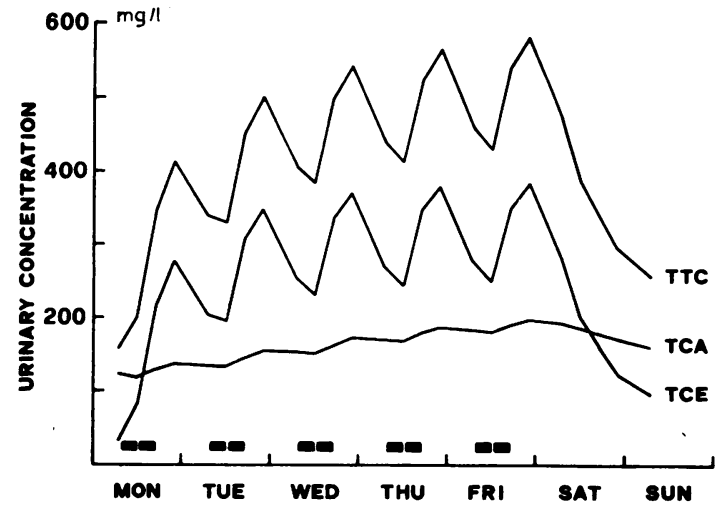

Fig. 1 Urinary concentrations of TCE, TCA and TTC during a steady-state week of exposure at $100 \mathrm{ppm}$. The urine samples are taken at $7 \mathrm{am}, 12 \mathrm{am}, 5 \mathrm{pm}$ and $10 \mathrm{pm}$. exposure periods: 8 am-12 am, 1 pm-5 pm.

The limit value for alveolar air concentrations of TRI (Table 3) and the limit value for urinary concentrations of TCE, TCA and TTC (Figure 1) obtained using the mathematical model are similar to those proposed from epidemiological studies (Lauwerys, 1975), or controlled exposure studies (Stewart et al., 1974). It must also be noted that the relationships established here between the degree of exposure and the excretion of TRI or of its metabolites are valid for the exposure only of sedentary workers. Increased amounts of physical activity will increase the quantity of TRI absorbed and consequently the amount of TRI and metabolites excreted. In such a case the increase in the urinary concentrations of the metabolites can be estimated using the mathematical relationships developed previously (Droz and Fernández, 1977).

HOURLY VARIATIONS IN EXPOSURE CONCENTRATION

The preceding biological limits of exposure are valid for a constant exposure concentration. To what extent these biological indicators are representative of situations with fluctuating exposures, such as usually occur in industry, must therefore be tested. Figure 2 gives the results of models 1 and 11 to 14 and shows the influence of hourly variations in the inspired concentration on the pulmonary elimination of TRI after identical mean exposures which took place on Thursday of a steady-state week. It can be seen that the variations in the exposure concentration have a major influence during the first few hours of elimination. The alveolar air concentrations thus obtained mainly reflect the end of the exposure. From the sixth hour onwards, the differences between the models are negligible and the alveolar

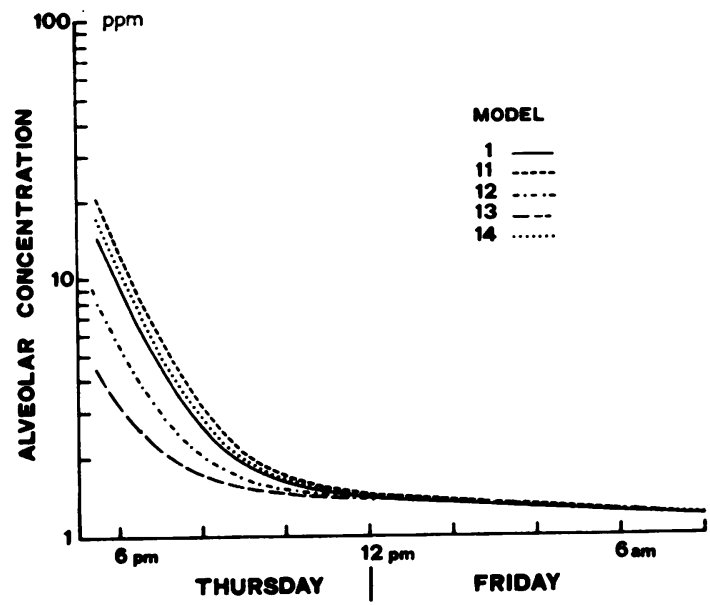

Fig. 2 Influence of hourly variations in the exposure concentration on Thursday of a steady-state week on the pulmonary elimination of TRI.

air concentrations thus become representative of the time-weighted average exposure concentration (TWA). These results agree well with those obtained experimentally during controlled exposures to fluctuating concentrations (Stewart et al., 1974). The evaluation of the degree of exposure can thus be based on the analysis of an alveolar sample taken at least six hours after the end of exposure.

Figure 3 shows the results of models 1 and 11 to 14 , with regard to the influence of hourly variations

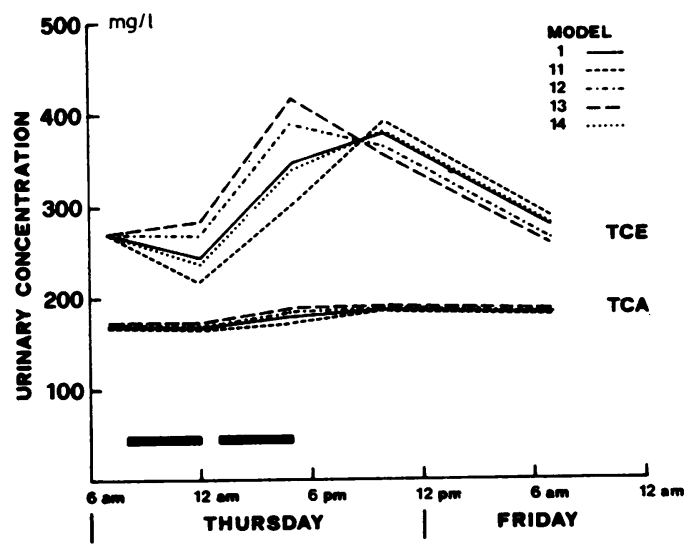

Fig. 3 Influence of hourly variations in the exposure concentration on Thursday of a steady-state week on the urinary concentrations of TCE and TCA. The urine samples are taken at $7 \mathrm{am}, 12 \mathrm{am}, 5 \mathrm{pm}$ and $10 \mathrm{pm}$. periods of exposure. 
in the inspired concentration on the urinary elimination of the metabolites. It appears that urinary concentrations of TCE are markedly influenced by fluctuations in the exposure concentration. This influence varies from sample to sample: it is in fact maximal for urine samples collected at 12 am and $5 \mathrm{pm}$, and low for those collected at $10 \mathrm{pm}$ and $7 \mathrm{am}$ the following day. The considerable variability of the urine samples collected at $12 \mathrm{am}$ and $5 \mathrm{pm}$ can be decreased if a sample collected throughout the whole work shift (extreme values $295-351 \mathrm{mg} / \mathrm{l}$ ) is considered. The urine samples taken at $5 \mathrm{pm}$ (end of work shift) are not representative, even qualitatively, of the average concentration of the second work period $(1 \mathrm{pm}-5 \mathrm{pm})$. The best representation of the average exposure concentration is obtained with samples taken at $10 \mathrm{pm}$ and $7 \mathrm{am}$ the following morning. The latter moreover is considered to be fairly reproducible.

From Figure 3 it can be seen that the TCA urinary concentrations are considerably less influenced than those of TCE by fluctuations in the inspired concentration. In fact, the maximal variations observed are lower than $5 \%$. Therefore, the timing of urine sampling influences only very slightly the results of the biological analysis of TCA, and consequently the estimated degree of exposure.

\section{DAILY VARIATIONS IN EXPOSURE CON- CENTRATION}

In addition to hourly fluctuations in the TRI absorbed, the average concentration also varies from day to day during occupational exposure. Models 4 to 10 schematically simulate these daily variations. The alveolar air concentrations obtained each day at $8 \mathrm{am}$ and $6 \mathrm{pm}$ are given in Table 4 . They are expressed as a percentage increase over those found during the steady-state week of exposure at $100 \mathrm{ppm}$ (model 1). From Table 4 it can be seen that the influence of daily variations in the inspired concen-

Table 4 Influence of daily fluctuations in the inspired concentration. Variation (\%) of the alveolar air concentrations of TRI compared with model 1 (Table 3)

\begin{tabular}{|c|c|c|c|c|c|c|c|c|}
\hline \multicolumn{2}{|l|}{ Day and time } & \multicolumn{7}{|c|}{ Model } \\
\hline & & 4 & 5 & 6 & 7 & 8 & 9 & 10 \\
\hline \multirow[t]{2}{*}{ Monday } & 8 am & 0 & 0 & 0 & 0 & 0 & 0 & 0 \\
\hline & $6 \mathrm{pm}$ & $95 \cdot 5$ & 0 & 0 & 0 & 0 & 0 & 0 \\
\hline \multirow[t]{2}{*}{ Tuesday } & 8 am & $63 \cdot 3$ & 0 & 0 & 0 & 0 & 0 & 0 \\
\hline & $6 \mathrm{pm}$ & $4 \cdot 6$ & $92 \cdot 7$ & 0 & 0 & 0 & $92 \cdot 7$ & $185 \cdot 5$ \\
\hline \multirow[t]{2}{*}{ Wednesday } & $8 \mathrm{am}$ & $31 \cdot 3$ & 50.5 & 0 & 0 & 0 & 50.5 & $101 \cdot 1$ \\
\hline & $6 \mathrm{pm}$ & $2 \cdot 8$ & $4 \cdot 5$ & $91 \cdot 1$ & 0 & 0 & $4 \cdot 5$ & $9 \cdot 0$ \\
\hline \multirow[t]{2}{*}{ Thursday } & $8 \mathrm{am}$ & $17 \cdot 2$ & $27 \cdot 8$ & $45 \cdot 0$ & 0 & 0 & $27 \cdot 8$ & 55.6 \\
\hline & $6 \mathrm{pm}$ & $1 \cdot 7$ & $2 \cdot 8$ & $4 \cdot 5$ & $90 \cdot 1$ & 0 & $92 \cdot 9$ & $185 \cdot 7$ \\
\hline \multirow[t]{2}{*}{ Friday } & $8 \mathrm{am}$ & $10 \cdot 0$ & $16 \cdot 1$ & $26 \cdot 1$ & $42 \cdot 2$ & 0 & $58 \cdot 3$ & $116 \cdot 5$ \\
\hline & $6 \mathrm{pm}$ & $1 \cdot 1$ & $1 \cdot 7$ & $2 \cdot 7$ & $4 \cdot 4$ & $89 \cdot 5$ & $6 \cdot 1$ & $12 \cdot 3$ \\
\hline Saturday & $8 \mathrm{am}$ & 5.9 & 9.6 & $15 \cdot 5$ & $25 \cdot 1$ & $40 \cdot 5$ & $34 \cdot 7$ & $69 \cdot 2$ \\
\hline
\end{tabular}

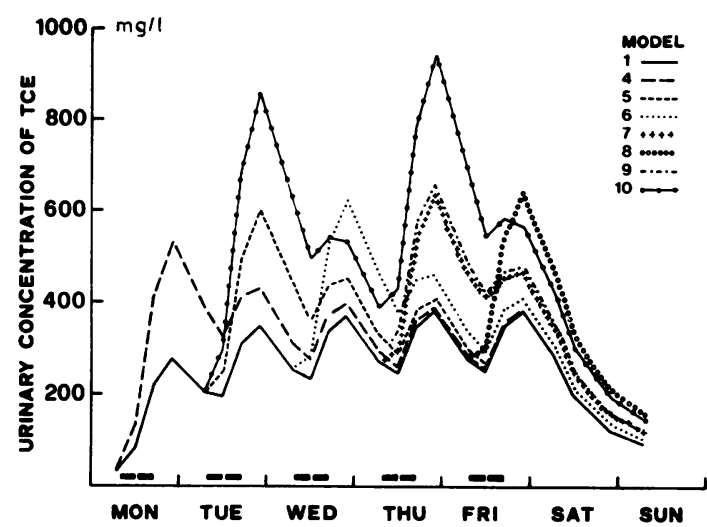

Fig. 4 Influence of daily variations in the exposure concentration during one week on the urinary concentrations of TCE. The urine samples are taken at 7 am, $12 \mathrm{am}, 5 \mathrm{pm}$ and $10 \mathrm{pm}$. exposure periods: $8 \mathrm{am}-12 \mathrm{am}$, $1 \mathrm{pm}-5 \mathrm{pm}$.

tration depends on the post-exposure time being considered. In fact, an increase from 100 to $200 \mathrm{ppm}$ approximately doubles the alveolar air concentrations at $6 \mathrm{pm}$, but does not induce the same effect 15 hours after exposure ( 8 am the following morning). Moreover, the influence of fluctuations in the exposure concentration is not identical each weekday: the increase in alveolar air concentrations after 15 hours post-exposure is maximal for the overexposure of Monday, and minimal for that of Friday. It can also be seen from Table 4 that an overexposure continues to influence the alveolar air concentrations at $8 \mathrm{am}$ for several days. It is thus difficult to estimate the degree of exposure using these concentrations. The pulmonary elimination of TRI measured at $6 \mathrm{pm}$ would appear to be the most suitable for evaluating the degree of exposure. However, it is strongly influenced by hourly variations in the exposure concentration.

Figure 4 gives the results of the influence of fluctuations in the inspired concentration (models 1 and 4 to 10) on the urinary excretion of TCE. An increase in the exposure concentration results in an almost identical increase in the urinary concentration, whatever urine sample is considered. However, it should be noted that the influence of a variation in the exposure concentration continues for several days. Under these conditions it is very difficult to interpret the results of a urine analysis of TCE. In fact, the concentration obtained reflects several days of exposure, each having an influence depending on the time lag between that exposure and sampling.

The results obtained for the urinary elimination of TCA are given in Figure 5 (models 1 and 4 to 10). 


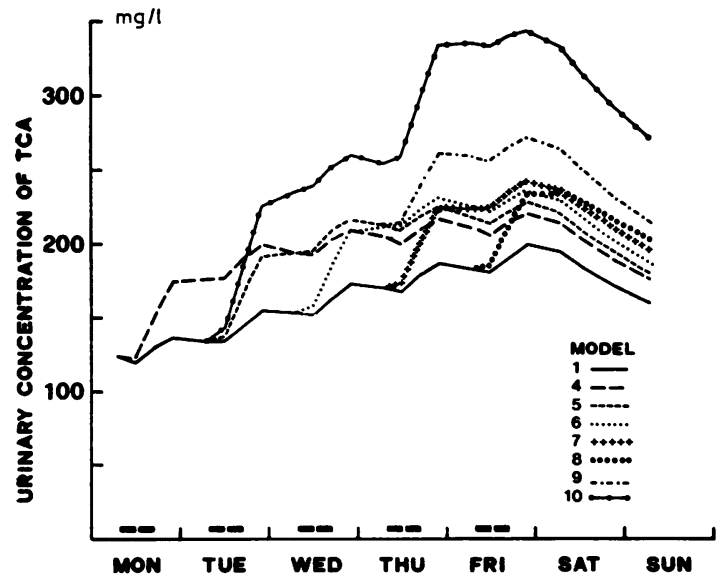

Fig. 5 Influence of daily variations in the exposure concentration during one week on the urinary concentrations of TCA. The urine samples are taken at $7 \mathrm{am}, 12 \mathrm{am}$, $5 \mathrm{pm}$ and $10 \mathrm{pm}$. $\square$ exposure periods: $8 \mathrm{am}-12 \mathrm{am}, 1 \mathrm{pm}$ $5 \mathrm{pm}$.

The influence of variations in the inspired concentration on the urinary excretion of TCA is totally different from that on the urinary excretion of TCE. This is due to the fact that TCA is eliminated very slowly from the body and is derived not only from TRI, but also from TCE (Fernández et al., 1977). The influence of variations in the exposure concentration is relatively low and the modification of the urinary excretion persists almost unchanged throughout the whole week. Therefore analysis of TCA cannot generally be related to the exposure concentration of the same day. It is more likely to be representative of the average concentration of the preceding days' exposures.

On the basis of the results given above, it is difficult to establish a good correlation between the average exposure of one day and the urinary excretion of the metabolites or pulmonary elimination of TRI. Each of these biological controls enables the degree of exposure to be determined, if the latter is constant from one day to another. However, these simple relationships are not valid for fluctuating exposure such as occurs in industry. This lack of direct correlation has probably accounted for the reported failures to devise a reliable method of biological monitoring.

\section{A POSSIBLE METHOD OF BIOLOGICAL} MONITORING

The main reason why it is not easy to estimate the degree of one single day's exposure by analysis of TRI or of its metabolites (TCE and TCA) is because the latter are eliminated relatively slowly from the body. In fact, at the beginning of the exposure which is to be monitored, the body burden of these different products is still large, especially with regard to TCA, and depends on the preceding days' exposures. This burden naturally influences the results of biological monitoring which will not be representative of one single day's exposure, but of the weighted mean of several days' absorption of TRI. Assuming that the elimination rate or concentration of a product is proportional to its body burden, the latter can be estimated before exposure by an analysis of urine or alveolar air. If the same measurement is performed after exposure, the absorption of TRI can thus be determined from the two values obtained. Such a relationship is given in Figure 6 for biological monitoring using alveolar air concentrations of TRI. This figure contains all the values calculated from models 1 to 10 (the values obtained on Saturday and Sunday are also included and represent the $0 \mathrm{ppm}$ exposures) and that corresponding to an isolated exposure at $300 \mathrm{ppm}$ : on the abscissa are the alveolar air concentrations $\left(\mathrm{C}_{\mathrm{ALV}}\right)$ measured just before the work shift $(8 \mathrm{am})$, on the ordinate the corresponding alveolar air concentrations measured 15 hours after the exposure ( $8 \mathrm{am}$ the following morning). The timing of sampling is based on the hourly variations in the exposure concentration. All the results of the models are distributed on four straight lines, each of which corresponds to a different exposure concentration $(0,100,200,300 \mathrm{ppm})$. Thus two

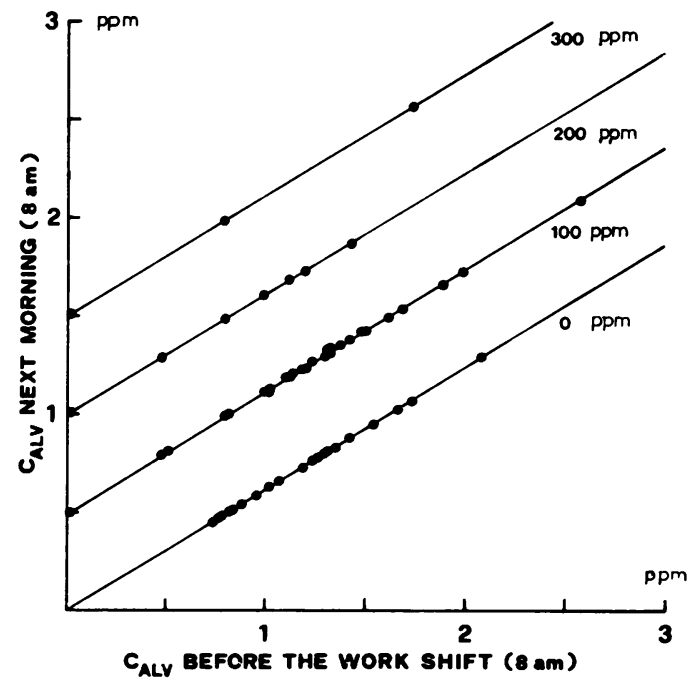

Fig. 6 Relationship between the exposure concentrations and the alveolar air concentrations $\left(C_{A L V}\right)$ of TRI before ( 8 am) and after (8 am the following morning) the exposure. results of models 1 to 10. The equations of the regression lines are given in Table 5. 
Table 5 Regression equations and correlation coefficients of the straight lines $y=a x+b$ of Figures 6 to 10

\begin{tabular}{ccccc}
\hline Figure & $\begin{array}{l}\text { Exposure } \\
\text { concentration } \\
(\text { ppm) }\end{array}$ & $\boldsymbol{a}$ & $\boldsymbol{b}$ & $\begin{array}{l}\text { Correlation } \\
\text { coefficient }\end{array}$ \\
\hline 6 & 0 & 0.619 & 0 & 1.000 \\
TRI & 100 & 0.618 & 0.499 & 0.999 \\
& 200 & 0.618 & 0.999 & 1.000 \\
7 & 300 & 0.619 & 1.497 & 1.000 \\
TCE & 0 & 0.336 & 3.68 & 0.996 \\
& 100 & 0.327 & 188 & 0.997 \\
8 & 200 & 0.331 & 373 & 0.999 \\
TCE & 300 & 0.349 & 554 & 0.999 \\
& 0 & 0.645 & 1.22 & 0.999 \\
9 & 100 & 0.639 & 122 & 0.999 \\
TCA & 200 & 0.637 & 243 & 0.999 \\
& 300 & 0.650 & 360 & 0.999 \\
10 & 0 & 0.801 & 6.21 & 0.996 \\
TCA & 100 & 0.842 & 43.8 & 0.995 \\
& 200 & 0.839 & 80.3 & 0.997 \\
& 300 & 0.835 & 123 & 0.992 \\
& 100 & 0.921 & 4.24 & 0.999 \\
& 200 & 0.948 & 14.5 & 0.998 \\
& 300 & 0.952 & 23.6 & 0.999 \\
& 0 & 0.941 & 39.0 & 1.000 \\
\hline
\end{tabular}

analyses of TRI in alveolar air, one before and the other after the exposure, theoretically enable the degree of exposure to be determined whatever day is considered and whatever the daily variations in the exposure concentration.

Figures 7 and 8 give the same relationship as in Figure 6 for the urinary concentrations of TCE. In the former, the concentration of TCE in the urine on the morning after the exposure $(7 \mathrm{am})$ is given as a function of that in the urine on the morning before the exposure. In Figure 8, instead of the urine of the following morning, the urine collected throughout the whole work shift is considered. Again, the sampling time is based on the hourly variations in exposure concentration. As with alveolar air concentrations of TRI, there appears to be a good correlation between the degree of exposure and the urinary excretion measured before and during or after exposure. With the same urine samples as for TCE, identical relationships are given in Figures 9 and 10 for TCA. For this metabolite, the scatter of the theoretical points is greater than for TCE. This is probably attributable to the fact that TCA is formed from two products, TRI and TCE, which have different kinetics in the body. The four different straight lines (Figure 10) are only very slightly separated compared to those obtained for TRI and TCE, implying that this biological indicator is not very sensitive to variations in the exposure concentration on the day in question.

This tentative method of biological monitoring therefore enables an unequivocal relationship to be set up between the TWA and the biological analyses of TRI and TCE. TCA is not included as it is not

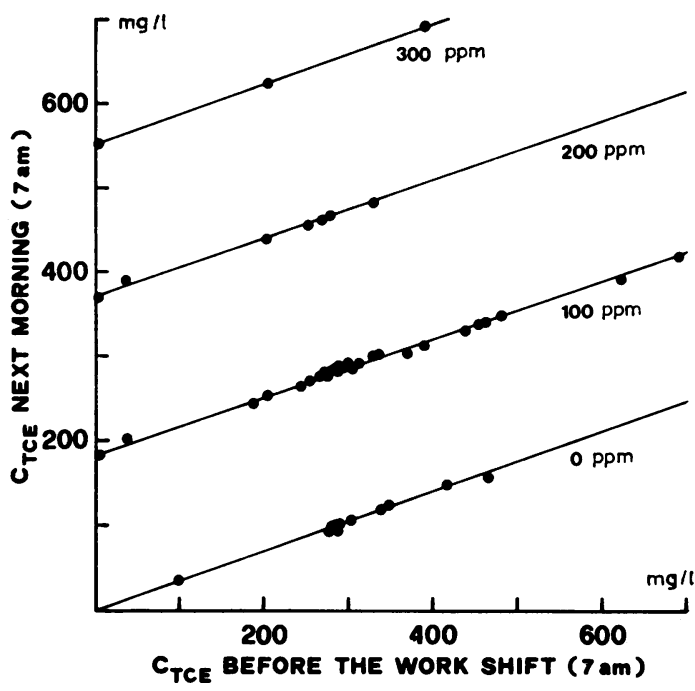

Fig. 7 Relationship between the exposure concentrations and the urinary concentrations of TCE ( $\left.C_{T C E}\right)$ the morning before $(7 \mathrm{am})$ and after the exposure. results of models 1 to 10. The equations of the regression lines are given in Table 5.

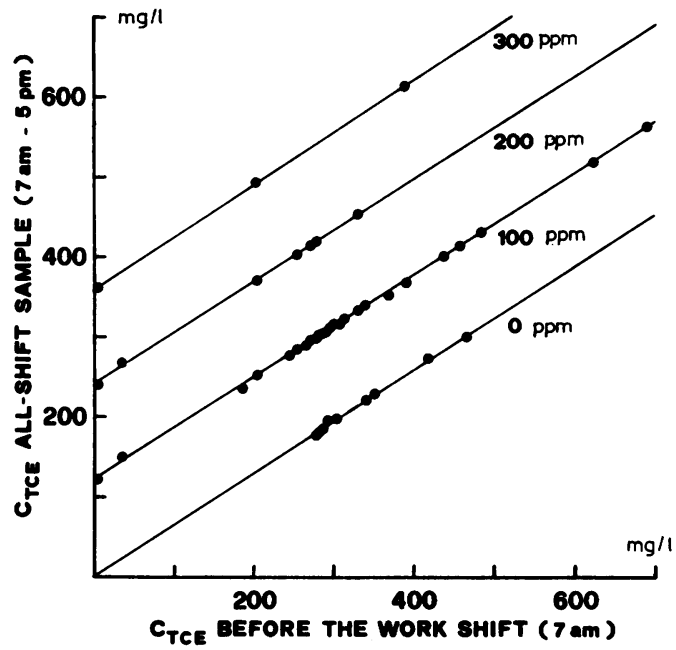

Fig. 8 Relationship between the exposure concentrations and the concentrations of TCE $\left(C_{T C E}\right)$ in the urine taken the morning before the exposure and those in the urine taken throughout the whole work shift. results of models 1 to 10 . The equations of the regression lines are given in Table 5.

very sensitive to changes in the inhaled concentration. It is interesting to compare these different biological controls of exposure as a function of their respective sensitivity. First, however, it must be 


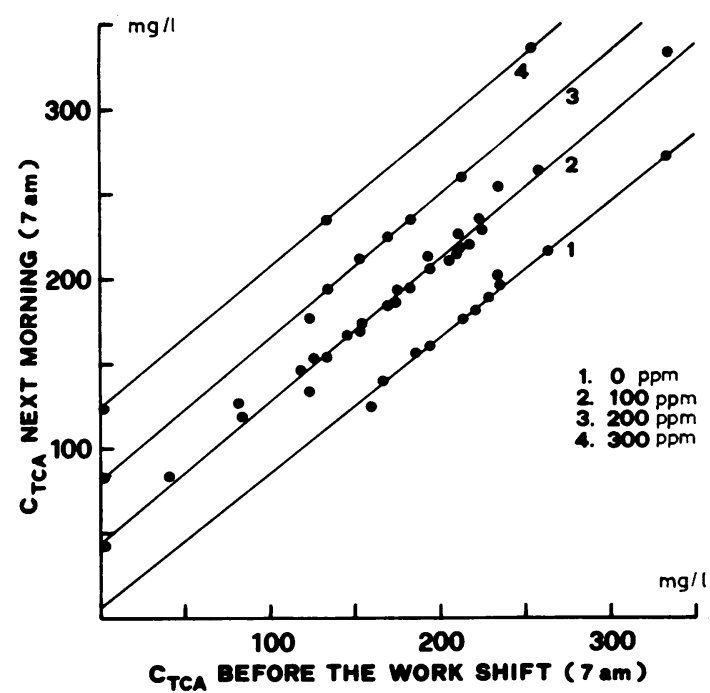

Fig. 9 Relationship between the exposure concentrations and the concentration of TCA $\left(C_{T C A}\right)$ in the urine the morning before $(7 \mathrm{am})$ and after the exposure. results of models 1 to 10. The equations of the regression lines are given in Table 5.

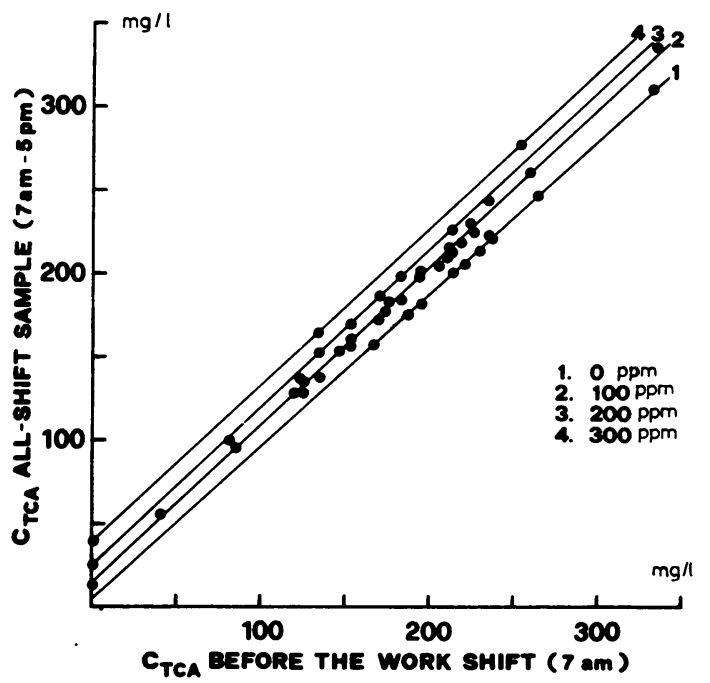

Fig. 10 Relationship between the exposure concentrations and the concentrations of TCA $\left(C_{T C A}\right)$ in the urine taken the morning before the exposure and those in the urine taken throughout the whole work shift. results of models 1 to 10. The equations of the regression lines are given in Table 5. noted that the sensitivity of these biological controls varies according to the concentration measured before the exposure; in fact, it is maximal for a zero initial concentration (isolated exposure). These different biological indicators can, however, be compared with respect to the concentrations occurring during a repeated exposure at $100 \mathrm{ppm}$ (Table 3 , Figure 1). The results obtained indicate that the biological monitoring proposed in Figure 7 with TCE is by far the most sensitive $(66 \%$ increase when the inspired concentration is doubled on Thursday), followed by that in Figure $8(41 \%)$ and by the alveolar air concentrations $(42 \%)$. Thus, biological monitoring of exposure to TRI by urine analysis of TCE the morning before and after the exposure seems theoretically to be the most suitable.

In addition, urine analysis of TCA before and after an exposure lasting more than one day could possibly enable the average degree of exposure during this period to be estimated. However, this would mean abandoning the concept of the average exposure concentration for an eight-hour period. Such monitoring should not be carried out in isolation, but could be used as a supplementary indication of the preceding days' exposures.

\section{Conclusions}

On the basis of the results obtained for the simulation of hourly variations in the exposure concentration, some recommendations can be made concerning the timing of alveolar air and urine sampling. It is in fact essential that the sample taken is representative of the whole day's exposure, that is, of the TWA. The alveolar air must, therefore, be analysed at least six hours after the end of the exposure (Figure 2). In practice, the most suitable moment seems to be the following morning, just before the next work shift. With regard to TCE, the most representative sample is undoubtedly the urine sample taken the morning after the exposure (Figure 3). When it is known that the inspired concentration does not vary greatly during the work shift, the urine collected throughout the whole exposure period can also subsequently be considered. Under no circumstances should a urine sample taken at the end of the work shift be used as a biological indicator. For a TCA analysis, the timing of sampling is of little importance (Figure 3). However, it has been shown that the urinary excretion of this metabolite is of limited interest for the biological monitoring of exposure.

The mathematical model used in this study has enabled theoretical biological exposure limits to be established for the urinary elimination of the metabolites (TCE, TCA and TTC) (Figure 1) and the pulmonary elimination of TRI (Table 3). 
However, examination of the influence of daily variations in the exposure concentration has shown that these biological limits must be applied only with caution. In fact, they can be used only when it is known from experience that the exposure concentrations do not vary from one day to the next. In practice, this could occur when the production is unchanged for several days, when TRI is used with automatic machines and when the workers involved do not change their work habits.

In all situations in which the exposure concentration varies considerably from one day to the next, the biological monitoring of exposure should be carried out according to the method proposed using two biological analyses (Figures 6-8). Theoretically the analysis of TCE is better than that of TRI with regard to sensitivity, but other technical factors such as timing, analysis and individual differences must also be taken into consideration in the final choice of the biological indicator. Moreover, some relationships similar to those developed here could be established for the blood concentrations of the metabolites. Blood analyses could thus in practice be preferable to those of urine, because of the smaller individual variations generally observed with the former.

Although the excretion of TCA is not directly and simply connected with the degree of exposure, it can be used for the qualitative evaluation of the preceding days' exposure. In fact, if the urinary concentration of TCA is lower than that corresponding to the exposure concentration estimated from TRI or TCE, it can be concluded that the average exposure of the preceding days was lower than that of the day in question. If the concentration of TCA is higher, then the previous exposure concentrations were higher, whereas if the two controls correspond, the exposure has been constant from one day to the next.

We are grateful to the Fonds National Suisse pour la Recherche Scientifique for its financial support.

\section{References}

Ahlmark, A., and Forssman, S. (1951). Evaluating trichloroethylene exposures by urinalyses for trichloroacetic acid. Archives of Industrial Hygiene and Occupational Medicine, 3, 386-398.
Droz, P. O., and Fernández, J. G. (1977). Effect of physical workload on retention and metabolism of inhaled organic solvents. A comparative theoretical approach and its applications with regard to exposure monitoring. International Archives of Occupational and Environmental Health, 38, 231-246.

Elkins, H. B. (1954). Analysis of biological materials as indices of exposure to organic solvents. Archives of Industrial Hygiene and Occupational Medicine, 9, 212-222.

Fernández, J. G., Droz, P. O., Humbert, B. E., and Caperos, J. R. (1977). Trichloroethylene exposure. Simulation of uptake, excretion and metabolism using a mathematical model. British Journal of Industrial Medicine, 34, 43-55.

Frant, R., and Westendorp, J. (1950). Medical control on exposure of industrial workers to trichloroethylene. Archives of Industrial Hygiene and Occupational Medicine, 1, 308-318.

Grandjean, E., Münchinger, R., Turrian, V., Haas, P. A., Knoepfel, H. K., and Rosenmund, H. (1955). Investigations into the effects of exposure to trichloroethylene in mechanical engineering. British Journal of Industrial Medicine, 12, 131-142.

Ikeda, M., Ohtsuji, H., Imamura, T., and Komoike, Y. (1972). Urinary excretion of 'total trichlorocompounds, trichloroethanol and trichloroacetic acid as a measure of exposure to trichloroethylene and tetrachloroethylene. British Journal of Industrial Medicine, 29, 328-333.

Lauwerys, R. (1975). Biological criteria for selected industrial toxic chemicals: A review. Scandinavian Journal of Work Environment and Health, 1, 139-172.

Lowry, L. K., Vandervort, R., and Polakoff, P. L. (1974). Biological indicators of occupational exposure to trichlorethylene. Journal of Occupational Medicine, 16, 98-101.

Müller, G., Spassovski, M., and Henschler, D. (1974). Metabolism of trichloroethylene in man. II. Pharmacokinetics of metabolites. Archives of Toxicology, 32, 283-295.

Nomiyama, K. (1971). Estimation of trichloroethylene exposure by biological materials. Internationales Archiv für Arbeitsmedizin, 27, 281-292.

Ogata, M., Takatsuka, Y., and Tomokuni, K. (1971). Excretion of organic chlorine compounds in the urine of persons exposed to vapours of trichloroethylene and tetrachloroethylene. British Journal of Industrial Medicine, 28, 386-391.

Pfäffli, P., and Backman, A. L. (1972). Trichloroethylene concentrations in blood and expired air as indicators of occupational exposure. A preliminary report. WorkEnvironment-Health, 9, 140-144.

Scherrer, J. (1967). In Physiologie du Travail (Ergonomie). I. Travail Physique. Energétique, pp. 154-235. Edited by Masson \& Cie: Paris.

Stewart, R. D., Hake, C. L., Peterson, J. E., and Dodd, H. C. (1974). Biologic standards for the industrial worker by breath analysis: trichloroethylene. I. Breath analysis for monitoring trichloroethylene exposures. HEW Publication No. $($ NIOSH) 74-133, 17-57.

Vesterberg, O., Gorczak, J., and Krasts, M. (1975). Exposition för triklorethylen. II. Metaboliter i blod och urin. Arbete och Hälsa, 15, 31-48. 